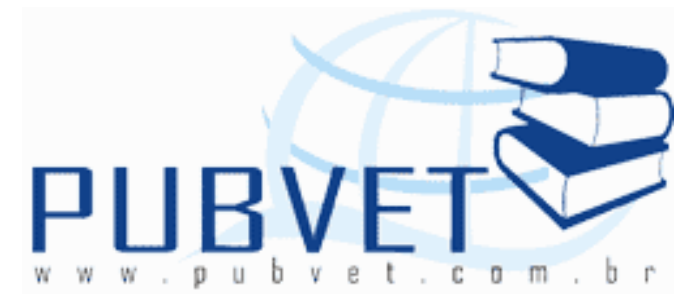

PUBVET, Publicações em Medicina Veterinária e Zootecnia.

\title{
Impactos ambientais produtivos gerados pela atividade camaroneira nos Municípios de Macaíba (RN) e São Gonçalo do Amarante (RN)
}

Israel José dos Santos Felipe ${ }^{1}$, Guilherme Dumaresq de Oliveira ${ }^{2}$

${ }^{1}$ Professor de Administração, Contabilidade e Gestão Financeira, UFRN, e-mail: israeljfelipe@gmail.com

2 Engenheiro de Segurança do Trabalho, UFRN, Técnico do IDEMA, e-mail: gdobr@yahoo.com.br

\section{Resumo}

Este trabalho demonstra o crescimento da atividade de criação de camarão (Carcinicultura) no Brasil e Rio Grande do Norte, destacando a produção mundial e nacional. Em seguida, expõe a importância das Áreas de Preservação Permanente (APP) - ecossistemas manguezais - como o meio ambiente para a biodiversidade (fauna e flora), como também, utilizado para o desenvolvimento da atividade camaroneira, sendo enfatizado o impacto ambiental nas áreas da atividade. As APPs que são objetos de estudo do artigo encontram-se nos Municípios de Macaíba e São Gonçalo do Amarante, ambos no estado do Rio Grande do Norte. Será ainda apresentada a existência de um plano responsável pelo acompanhamento da recuperação das APP degradadas, o Plano de Recuperação de Área de Preservação Permanente (PRAPP), utilizado pelo Órgão responsável pelo Meio Ambiente no Rio Grande do Norte. Concluindo-se que há uma legislação específica que protege as APPs, contudo é transgredida por grande parte das empresas carcinicultoras que atuam 
FELIPE, I.J.S. e OLIVEIRA, G.D. Impactos ambientais produtivos gerados pela atividade camaroneira nos Municípios de Macaíba (RN) e São Gonçalo do Amarante (RN). PUBVET, Londrina, V. 6, N. 31, Ed. 218, Art. 1453, 2012.

nessas regiões. Por fim, há muito trabalho a ser feito pelas autoridades competentes e todos os esforços feitos em razão da preservação de áreas ambientais são válidos e contribuem para a diminuição do impacto das atividades predatórias nos mangues e nos ecossistemas naturais.

Palavras-chave: Carcinicultura; Desmatamento; Gestão Ambiental; Impactos Ambientais.

\title{
Productive environmental impacts generated by the camaroneira activity in the municipalities of Macaiba (RN) and São Gonçalo do Amarante (RN)
}

\begin{abstract}
This work demonstrates the growth of creative activity of shrimp (shrimp farming) in Brazil and Rio Grande do Norte, highlighting national and worldwide production. Then exposes the importance of Areas of permanent preservation (APP)-mangrove ecosystems-such as the environment for biodiversity (fauna and flora), but also used for the development of camaroneira activity, being emphasized the environmental impact in the areas of activity. The APPs that are objects of study of the article can be found in the municipalities of Brazil and São Gonçalo do Amarante, both in the State of Rio Grande do Norte. Will also be presented for the existence of a plan responsible for monitoring the recovery of degraded APP, the recovery plan of Permanent preservation area (PRAPP), used by the body responsible for Environment in Rio Grande do Norte. Concluding that there is specific legislation that protects the APPs, however is infringed by a large part of the carcinicultoras companies that operate in these regions. Finally, there is much work to be done by the competent authorities and all efforts made on grounds of preserving environmental areas are valid and contribute to reducing the impact of predatory activities in mangroves and natural ecosystems.
\end{abstract}

Keywords: Shrimp Farming; Deforestation; Environmental Management; Environmental Impacts. 
FELIPE, I.J.S. e OLIVEIRA, G.D. Impactos ambientais produtivos gerados pela atividade camaroneira nos Municípios de Macaíba (RN) e São Gonçalo do Amarante (RN). PUBVET, Londrina, V. 6, N. 31, Ed. 218, Art. 1453, 2012.

\section{Introdução}

A Palavra "Carcinicultura" possui origem do grego karkínos, que significa caranguejo mais cultura, com conotação de cultivo de início referia-se "cultivo de caranguejos". Porém o termo passou a ser utilizado para o cultivo de crustáceo, atualmente, é utilizado para o cultivo de camarão, principalmente devido ao desenvolvimento desta atividade. A Carcinicultura, também conhecida como atividade camaroneira, é considerada uma importante atividade econômica em zonas costeiras por serem locais propícios ao cultivo da espécie.

Devido ao grande crescimento a nível mundial do consumo do camarão, nas quatro últimas décadas, principalmente, em razão da demanda dos EUA, Japão e de alguns países europeus. Regiões produtoras como Ásia, América Central e alguns países da América do Sul, como o Equador, realizam a construção indiscriminada de tanques de carcinicultura e canais de abastecimento de água, visto que a atividade é realizada em cativeiros ou viveiros.

No Brasil, a indústria de pescado apresenta um panorama de desenvolvimento que varia apreciavelmente entre os seus dois grandes componentes: a pesca e a aqüicultura. Com $8,5 \mathrm{mil} \mathrm{km}$ de costa marítima que abrange uma Zona Econômica Exclusiva de 4,3 milhões de $\mathrm{Km}^{2}$, com $12 \%$ do total de reserva de água doce do Planeta e mais 02 milhões de hectares de terras alargadas, além do clima favorável, o grande potencial do Brasil para a produção de pescado ainda não foi realizado, principalmente no que se refere à aqüicultura marinha e de água doce, e à pesca oceânica. $O$ valor gerado pelo setor pesqueiro do Brasil representa apenas $0,4 \%$ do PIB nacional (ASSOCIAÇÃO BRASILEIRA DE CRIADORES DE CAMARÃO, 2007).

Há um consenso nacional de que o Brasil oferece amplas e variadas alternativas para o desenvolvimento vigoroso de sua aqüicultura marinha quanto de água doce. Comercialmente, o camarão marinho é cultivado e é o 
FELIPE, I.J.S. e OLIVEIRA, G.D. Impactos ambientais produtivos gerados pela atividade camaroneira nos Municípios de Macaíba (RN) e São Gonçalo do Amarante (RN). PUBVET, Londrina, V. 6, N. 31, Ed. 218, Art. 1453, 2012.

principal segmento da aqüicultura brasileira cuja produção, em 2008, foi estimada em 70.000 toneladas em sua maior parte para exportação, seguido pela tilápia com 67.850 toneladas destinada ao mercado nacional. (ASSOCIAÇÃO BRASILEIRA DE CRIADORES DE CAMARÃO, 2009). Logo abaixo, o gráfico 01 ilustra o comparativo da produção de camarão cultivado de dois grandes produtores da América do Sul.

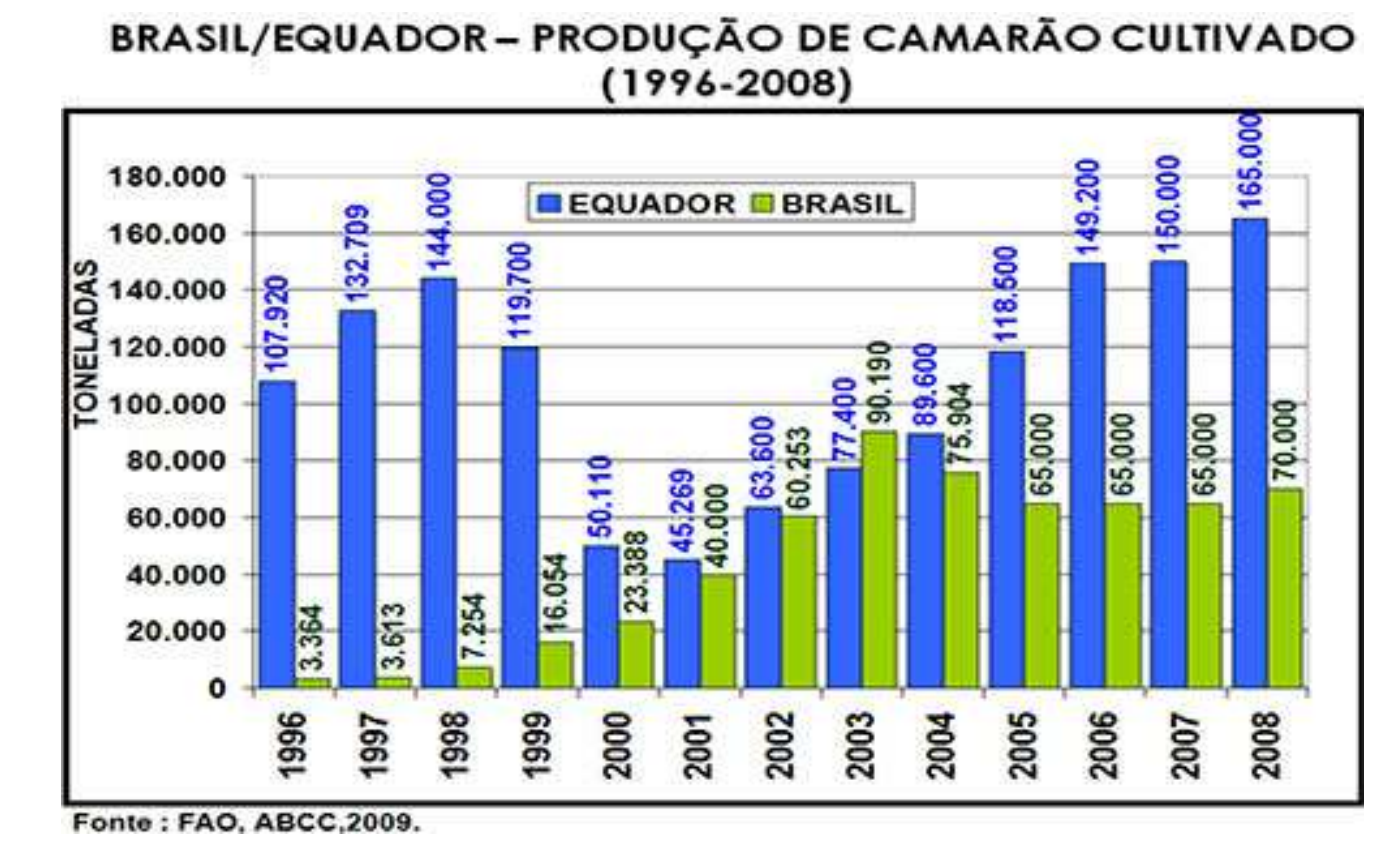

Gráfico 1- Produção de Camarão Cultivado. (FAO, ABCC, 2009).

\subsection{A Carcinicultura no Rio Grande do Norte}

A atividade da Carcinicultura no Rio Grande do Norte tem se desenvolvido muito nos últimos anos, colocando o Estado entre os maiores produtores de camarão cultivado do país, chegando a produzir 07 mil toneladas por ano. Tal posição justifica-se, principalmente, pela condição climática favorável e disponibilidade de áreas propícias à exploração da atividade, o que tem atraído a atenção de muitos investidores para o Rio Grande do Norte. Recentemente, devido à introdução de novas tecnologias, em toda cadeia produtiva, tem modificado positivamente os níveis de sobrevivência final, proporcionando um incremento na produtividade e, 
FELIPE, I.J.S. e OLIVEIRA, G.D. Impactos ambientais produtivos gerados pela atividade camaroneira nos Municípios de Macaíba (RN) e São Gonçalo do Amarante (RN). PUBVET, Londrina, V. 6, N. 31, Ed. 218, Art. 1453, 2012.

consequentemente, na produção total de camarão cultivado no Estado. No entanto, a rápida expansão do setor tem gerado grande concentração de fazendas de produção. A questão da distribuição geográfica das unidades de cultivo implantadas e em implantação, somada à intensificação dos cultivos, tem levado o setor a preocupar-se com capacidade de suporte dos tanques, no que diz respeito à qualidade da água e a assistência técnica para os pequenos produtores. Outro fator observado é a dificuldade encontrada pelos produtores para regularizar sua situação junto aos órgãos licenciadores da atividade, haja vista a discrepância nos dados oficiais sobre número de fazendas, produção total e condições de cultivo.

\section{A Legislação Ambiental, Impactos Ambientais e o Programa de Recuperação de Área de Preservação Permanente (PRAPP)}

A atividade da carcinicultura costuma ficar localizada nas proximidades de manguezais por serem propícias ao cultivo da espécie e por serem ricos em nutrientes. Tais áreas, segundo o IX do Art. $3^{\circ}$ da Resolução no 303/2002 do Conselho Nacional do Meio Ambiente - CONAMA, constituem-se, em toda sua extensão, em Área de Preservação Permanente (APP). A atividade, nas proximidades destes locais, utiliza as águas tanto para captação, criação dos camarões, quanto para o lançamento final dos efluentes gerados pelo empreendimento, principalmente no período da despesca do camarão. Sendo assim, devido aos impactos negativos de grandes proporções sobre os recursos hídricos e a biodiversidade a atividade caracteriza-se como potencialmente poluidora.

Nesta atividade ocorre a construção de canais e tanques, que em linha gerais causam, impactos as mudanças na drenagem, desvio ou impedimento do fluxo das marés, mudanças nas características físico-químicas do substrato, entre outros. Na tabela abaixo, são descritos alguns tipos de impactos relacionados à carcinicultura. 
FELIPE, I.J.S. e OLIVEIRA, G.D. Impactos ambientais produtivos gerados pela atividade camaroneira nos Municípios de Macaíba (RN) e São Gonçalo do Amarante (RN). PUBVET, Londrina, V. 6, N. 31, Ed. 218, Art. 1453, 2012.

\section{Tabela 1- Impactos gerados pela atividade camaroneira}

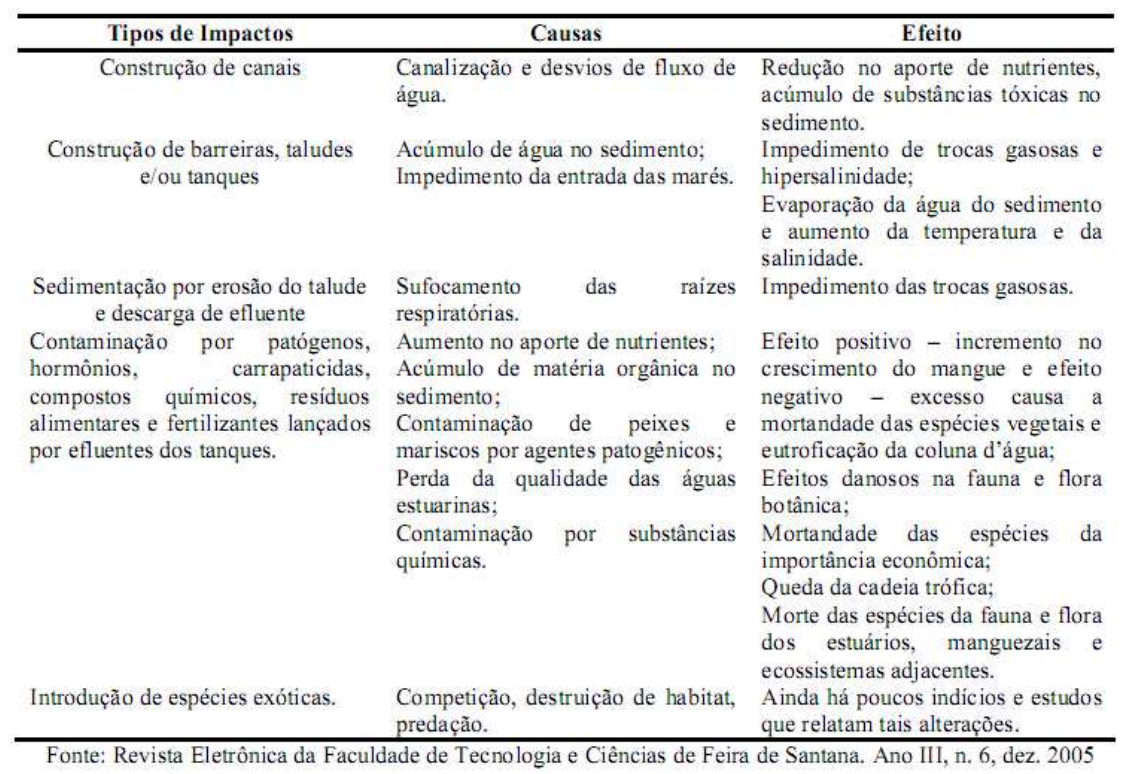

Em razão da potencialidade danosa da atividade ao meio ambiente, o Conselho Nacional de Meio Ambiente (CONAMA) editou a Resolução 312/2002, que contém regras específicas para a atividade de criação de camarões. Onde em seu Art 20, ficou estabelecida a proibição da atividade de carcinicultura em manguezal. Pois estas Áreas surgem com objetivo de proteção ambiental a biodiversidade, recursos hídricos, a paisagem, a estabilidade geológica, o fluxo gênico da fauna e flora, proteger o solo e assegura o bem estar das populações humanas. Podemos citar alguns dos principais benefícios trazidos pelo mangues como meio de preservação para o ecossistema marítimo e fluvial:

a) Fonte de matéria orgânica particulada e dissolvida para as águas costeiras adjacentes, constituindo a base de cadeia trófica com espécies de importância econômica e/ou ecológica;

b) Área de abrigo, reprodução, desenvolvimento e alimentação de espécies marinha, estuarinas, límnicas e terrestres, além de pouso de aves migratórias; 
FELIPE, I.J.S. e OLIVEIRA, G.D. Impactos ambientais produtivos gerados pela atividade camaroneira nos Municípios de Macaíba (RN) e São Gonçalo do Amarante (RN). PUBVET, Londrina, V. 6, N. 31, Ed. 218, Art. 1453, 2012.

c) Proteção de linha de costa contra erosão, assoreamento dos corpos d'água adjacentes, prevenção de inundações e proteção contra tempestades;

d) Manutenção da biodiversidade da região costeira;

e) Absorção e imobilização de produtos químicos (por exemplo, metais pesados), filtro de poluentes e sedimentos, além de tratamento de efluentes em seus diferentes níveis;

f) Fonte de recreação e lazer, associada ao seu apelo paisagístico e alto valor cênico; e,

g) Fonte de proteína e produtos diversos, associados à subsistência de comunidades tradicionais que vivem em áreas vizinhas aos manguezais.

Essas áreas são protegidas pela Lei Federal no 4.771/64 e para supressão da vegetação dessas áreas só pode ocorrer com autorização do poder executivo federal, em caso de obras de interesse coletivo. Sendo assim, a responsabilidade de recomposição de uma APP que tenha sido degradada, é do proprietário da terra independentemente da culpa pela degradação ocorrida. Caso venha ocorrer o Órgão Ambiental do Estado do Rio Grande do Norte deverá estabelecer como medida corretiva o Plano de Recuperação de Área de Preservação Permanente - PRAPP, regido pela Lei Federal no 4.771/65, consiste em informar, levantar e propor a recuperação das APPs degradadas, em conseqüência da atividade. As informações básicas que devem constar no PRAPP:

- Identificação do Empreendedor;

- Identificação do Empreendimento;

- Locais e vias de acesso; e,

- Projeto de Recuperação de Área de Preservação Permanente. 
FELIPE, I.J.S. e OLIVEIRA, G.D. Impactos ambientais produtivos gerados pela atividade camaroneira nos Municípios de Macaíba (RN) e São Gonçalo do Amarante (RN). PUBVET, Londrina, V. 6, N. 31, Ed. 218, Art. 1453, 2012.

Esse último item apresenta uma grande importância no PRAPP, pois consta identificar e descrever todas as características físicas do relevo, solo, recursos hídricos, tipos de vegetação local, tipo da vegetação degradada e da utiliza para recuperação. Devendo ser apresentado os procedimentos que serão adotados (preparo da área e plantio, escolha das espécies a serem plantadas, limpeza da área, recuo dos diques, alinhamento e espaçamento entre as mudas), sendo estabelecido um cronograma físico de execução de todas as obras. As etapas podem estar programadas mensal, bimestral, trimestral ou semestralmente. Devendo ser apresentado neste plano a equipe técnica responsável pela elaboração do PRAPP e relatório fotográfico mostrando o andamento do plano. Por final, o plano deve ser protocolado junto ao Órgão Ambiental para as devidas providências técnicas.

\section{O Caso do Município de Macaíba}

A partir deste momento, o artigo ira focalizar a potencialidade dos impactos ambientais causados pela devastação da flora do ecossistema manguezal, pela indústria camaroneira no município de Macaíba do Rio Grande do Norte. O método adotado foi a pesquisa qualitativa, que utilizou, como instrumentos de coleta de dados, entrevistas não estruturas com técnicos ambientais do Órgão Ambiental do estado do Rio Grande do Norte, documentos fornecidos pelos técnicos e relatório de campo da visita.

Pesquisas realizadas pelo Órgão Ambiental do Rio Grande do Norte sobre o desmatamento de mata ciliar e principalmente mangues, nos revelam o seguinte resultado. A quantidade de fazendas que operam de forma irregular, por falta de licenciamento como também por avanço das construções dos tanques sobre áreas de preservação ambiental, estão quantificados na tabela abaixo: 
FELIPE, I.J.S. e OLIVEIRA, G.D. Impactos ambientais produtivos gerados pela atividade camaroneira nos Municípios de Macaíba (RN) e São Gonçalo do Amarante (RN). PUBVET, Londrina, V. 6, N. 31, Ed. 218, Art. 1453, 2012.

Tabela 2- Empreendimentos Irregulares em Macaíba.

\begin{tabular}{|c|c|c|c|c|}
\hline \multicolumn{5}{|c|}{ EMPREENDIMENTOS IRREGULARES } \\
\hline Empreendimentos & Área do Emp.(ha) & $\begin{array}{c}\text { Area de mangue } \\
\text { desm. (ha) }\end{array}$ & $\begin{array}{c}\text { Area de ocup. } \\
\text { Irregular (ha) }\end{array}$ & Emp. Sem licença \\
\hline Total de 16 & $\mathbf{1 9 , 7 6}$ & $\mathbf{1 , 8 5}$ & $\mathbf{3 , 1 8}$ & $\mathbf{1 5}$ \\
\hline
\end{tabular}

Fonte: IDEIMA, 2008.

Observando a tabela 2, logo acima, percebe-se que o Município de Macaíba apresenta 16 fazendas carcinicultoras, com cerca de 19,76 ha de área ocupada. Deste total, apenas 2,07\%, ou seja, 1 empreendimento tem algum tipo de licença. Do total da área do empreendimento, 52,12\% ocupam área de Área de Preservação Permanente (APP). A área de ocupação irregular destes empreendimentos corresponde a 16,09\%, ou seja, eles estão invadindo de forma ilegal as áreas de preservação ambiental (APA), protegidas pelo Decreto no 14.363, de 22 de março de 1999.

Apesar de conter essa grande quantidade de empresas irregulares, não se deve esquecer que existe uma parcela que atua de forma regular e licenciada pelo IDEMA no município de Macaíba, como mostra a tabela abaixo:

Tabela 3- Empreendimentos Regulares em Macaíba.

\begin{tabular}{l}
\hline \multicolumn{4}{c}{ EMPREENDIMENTOS REGULARES } \\
$\qquad$\begin{tabular}{c|c|c|}
\hline & $\begin{array}{c}\text { Area do } \\
\text { Emp.(ha) }\end{array}$ & $\begin{array}{c}\text { Area de ocup. } \\
\text { Irreqular (ha) }\end{array}$ \\
\hline Total de 11 empresas & $\mathbf{8 9 , 2 6}$ & $\mathbf{0 , 1 1}$ \\
\hline
\end{tabular} \\
\hline
\end{tabular}

Fonte: IDEIMA, 2008.

Dos 11 empreendimentos, apenas um deles, ocupa área de APP, cerca de 0,11 ha. Neste caso, o IDEMA concedeu a LO (Licença de Operação) condicional para funcionamento provisório da empresa, que terá por obrigatoriedade de se adequar as normas ambientais de ocupação de terras. Vale salientar que, as atividades desta empresa estão sendo acompanhadas e monitoradas através da implantação do PRAPP nesta área. 
FELIPE, I.J.S. e OLIVEIRA, G.D. Impactos ambientais produtivos gerados pela atividade camaroneira nos Municípios de Macaíba (RN) e São Gonçalo do Amarante (RN). PUBVET, Londrina, V. 6, N. 31, Ed. 218, Art. 1453, 2012.

\section{O Caso do Município de São Gonçalo do Amarante}

Através da pesquisa realizada pode-se constatar que no Município de São Gonçalo do Amarante, há 22 empreendimentos, dos quais 16 deles não tinham algum tipo de licença ambiental, numa área total de 103, 58 ha. Para tal ocupação, foi desmatado 23,99 ha de área de mangue, totalizando 9,5 ha de Área de Preservação Permanente (APP). Os dados acima citados podem ser vistos e conferidos na tabela logo a seguir:

Tabela 4- Empreendimentos Irregulares em São Gonçalo do Amarante.

\begin{tabular}{|c|c|c|c|c|}
\hline \multicolumn{5}{|c|}{ EMPREENDIMENTOS IRREGULARES } \\
\hline Empreendimentos & $\begin{array}{c}\text { Area do Emp. } \\
\text { (ha) }\end{array}$ & $\begin{array}{c}\text { Area de mangue } \\
\text { desm. (ha) }\end{array}$ & $\begin{array}{l}\text { Area de } \propto \text { cup. } \\
\text { Irregular (ha) }\end{array}$ & $\begin{array}{l}\text { Emp. Sem } \\
\text { licenca }\end{array}$ \\
\hline Total de 22 & 103,58 & 23,99 & 9,5 & 16 \\
\hline
\end{tabular}

Fonte: IDEMA, 2008.

Tabela 5- Empreendimentos Regulares em São Gonçalo do Amarante.

\begin{tabular}{l}
\hline EMMPEENDIMENTOS REGULARES \\
$\qquad$\begin{tabular}{c|c|c|}
\hline & $\begin{array}{c}\text { Area do } \\
\text { Emp.(ha) }\end{array}$ & $\begin{array}{c}\text { Area de ocup. } \\
\text { Irreqular (ha) }\end{array}$ \\
\cline { 2 - 3 } & 385,3 & $\mathbf{1 3 , 3 3}$ \\
\hline Total de 16 empresas & 38, \\
\hline
\end{tabular} \\
\hline
\end{tabular}

Já no caso dos empreendimentos regulares, dos 16 empreendimentos regulares (ver tabela 4), há uma ocupação de apenas 3,45\% de APP, cerca de 13,33 ha (ver tabela 5). Nestes empreendimentos que ocupam área de APP, o IDEMA já está intervindo através de liminares da justiça para caçar as licenças ou forçar a regularização das propriedades. Pois todas elas devem estar enquadradas nas normas ambientais de legislação e irão ser monitoradas pelo PRAPP implantando em cada uma delas. 
FELIPE, I.J.S. e OLIVEIRA, G.D. Impactos ambientais produtivos gerados pela atividade camaroneira nos Municípios de Macaíba (RN) e São Gonçalo do Amarante (RN). PUBVET, Londrina, V. 6, N. 31, Ed. 218, Art. 1453, 2012.

\section{Considerações Finais}

É importante salientar que todos os dados obtidos nesta pesquisa estão em conformidade com o levantamento oficial realizado pelo IDEMA através de fotos e estudo topográfico por GPS.

Através destes dados, pode-se concluir que a maior área ocupada pelas fazendas de criação de camarão em Macaíba é ocupada por 11 empresas regulares (com licença ambiental), porém 16 empresas atuam de forma irregular (sem licença ambiental). Não diferentemente disso, em São Gonçalo do Amarante, há 16 empresas regulares, número muito inferior as 22 empresas que atuam de forma irregular nessa região, sem algum tipo de licença ou com a mesma vencida. É preciso então se ter uma maior fiscalização por parte das autoridades locais para regularização e cumprimento das leis ambientais.

Há muito ainda a se fazer sobre a influência desses impactos ambientais, por exemplo, estudos sobre o lançamento de efluentes dos tanques de criação nas lagoas dos municípios de Macaíba e São Gonçalo do Amarante. Tem se apenas como entendimento qualitativo que grande quantidade desses efluentes ricos em Nitrogênio e Fósforo são lançados constantemente. Por sua vez, capazes de proliferar o surgimento de microorganismos, que diminuem o nível de oxigênio presente nas lagoas reduzindo significamente a biodiversidade local existente.

\section{REFERÊNCIAS}

ABDL (ASSOCIAÇÃO BRASILEIRA PARA O DESENVOLVIMENTO DE LIDERANÇAS). São Paulo. Apresenta Informações sobre a Carnicicultura no Rio Grande do Norte. Disponível em: <http://www.abdl.org.br/article/view/255/1/89>. Acesso em: 29 de Abril de 2007.

COELHO JUNIOR, C \& Novelli, Yara S. Considerações Teóricas e Práticas Sobre o Impacto da Carcinicultura nos Ecossistemas Costeiros Brasileiros, com Ênfase no Ecossistema Manguezal. Laboratório BIOMA, Instituto Oceanográfico da Universidade de São Paulo.

IDEMA (INSTITUTO DE DESENVOLVIMENTO ECONÔMICO E MEIO AMBIENTE). Dados Referentes á Quantidade de Fazendas de Criação de Camarão Irregulares e Regulares e suas Respectivas Áreas de Ocupação e Informações Referentes e ao Plano de Recuperação de Área Preservação Permanente, 2007. 
Monteiro Uchoa Hislei, L; Souza e Marques, G; Parente Maia, L; Ferreira Fernando, L \& Lacerda, L. Evolução das Áreas de Manguezal do Litoral Norte Nordeste Brasileiro entre 1978 e 2004. Instituto de Ciências do Mar, Universidade Federal do Ceará. Fortaleza, Ceará.

SANTOS, M; Carvalho Santos, M; Carneiro da Silva, G \& Souza Freitas, T. Proposta de Implementação de um Sistema Para Monitoramento e Controle na Carcinicultura. Diálogos \& Ciência - Revista Eletrônica da Faculdade de Tecnologia e Ciências de Feira de Santana. Ano III, n. 6, dez. 2005.

OLIVEIRA, G.D. de; MATTOS, K. M. da C. Impactos ambientais provocados pela indústria de camarão no município de Nísia Floresta (RN). Revistas Gerenciais, São Paulo, v.6, n. 2, p. 183$188,2007$.

DIAS, Gilka Da Mata. Cidade Sustentável - fundamentos legais, política urbana, meio ambiente, saneamento básico/Gilka da Mata Dias - Natal: Ed. Do Autor, 2009. 384p.

BRASIL CONGRESSO. Lei no 4.771, de 15 de setembro de 1965. Rege o Plano de Recuperação de Área de Preservação Permanente (PRAPP). Disponível em:

<http://www.planalto.gov.br/CCIVIL/LEIS/L4771.htm>. Acesso em: 10 de agosto de 2009.

INSTITUTO DE DESENVOLVIMENTO SUSTENTÁVEL E MEIO AMBIENTE DO RIO GRANDE DO NORTE (IDEMA-RN). Decreto no. 14.639 de 22 de março de 1999. Dispõe sobre as Áreas de Preservação Ambiental. Disponível em:

$<$ http://www.rn.gov.br/secretarias/idema/legislacaoctd.asp?id=80 >. Acesso em 10 de agosto de 2009.

CONSELHO NACIONAL DE MEIO AMBIENTE (CONAMA). Resolução n0312, de 10 de outubro de 2002. Dispõe sobre licenciamento ambiental dos empreendimentos de carcinicultura na zona costeira. Disponível em: <http://www.mma.gov.br/port/conama/res/res02/res31202.html>. Acesso em 10 de agosto de 2009.

CONSELHO NACIONAL DE MEIO AMBIENTE (CONAMA). Resolução n0303, de 20 de março de 2002. Dispõe sobre parâmetros, definições e limites de Áreas de Preservação Permanente. Disponível em: http://www.mma.gov.br/port/conama/res/res02/res30302.html. Acesso em 10 de agosto de 2009. 